AT - TADBIR

JURNAL ILMIAH MANAJEMEN

\title{
Bagaimana Iklim Etis Dan Gaya Kepemimpinan Berpengaruh Terhadap Efektifitas Pemimpin?
}

\author{
R. Iqbal Robbie*, Ardik Praharjo \\ Fekultas Ekonomi dan Bisnis, Universitas Muhammadiyah Malang \\ e-mail: Iqbal_robbie@umm.ac.id*
}

\begin{abstract}
This study aims to determine the relationship between ethical climate and leadership effectiveness in companies with ethical leadership variables as intervening variables. Ethical leadership is based on the diversity of situations and conditions in the company and personal values within the leader so as to allow conflict or good synergy between employees. The population of this study were all permanent employees under the medical services division, especially the nursing field, totaling 133 employees at the Muhammadiyah University Hospital, Malang. The research variables will be elaborated through a questionnaire which will be distributed to respondents based on the total amount, because all pupulation is used as research objects. Data collected will be processed using the analysis "Partial least square (PLS)". This is because the PLS analysis is able to measure variables that cannot be measured directly but are interrelated. The results showed that the ethical climate and ethical leadership and influence on leadership effectiveness at Malang Muhammadiyah Hospital.
\end{abstract}

Keywords: ethical climate, ethical leadership, effectiveness leadership

\begin{abstract}
Abstrak
Penelitian ini bertujuan untuk mengetahui hubungan antara iklim etis dengan efektifitas kepemimpinan dalam perusahaan dengan variabel kepemimpinan etis sebagai variabel intervening. Kepemimpinan etis didasari oleh keberagaman situasi dan kondisi di perusahaan dan nilai personal dalam diri pemimpin sehingga memungkinkan terjadinya konflik atau sinergi yang baik diantara para karyawan. Populasi dari penelitian ini adalah seluruh karyawan tetap yang berada dibawah divisi pelayanan medik khususnya bidang keperawatan berjumlah 133 karyawan di RS Universitas Muhammadiyah Malang. Variabel penelitian akan dijabarkan melalui kuesioner yang akan disebarkan kepada responden berdasarkan jumlah keseluruhan, karena seluruh pupulasi digunakan sebagai objek penelitian. Data yang terkumpul akan diolah dengan menggunakan analisis "Partial least square (PLS)". Hal ini karena analisis PLS mampu mengukur variabel yang tidak dapat diukur secara langsung namun saling berkaitan. Hasil penelitian menunjukkan bahwa iklim etis dan kepimpinan etis dan berpengaruh terhadap efektifitias kepimpinan pada Rumah Sakit Muhammadiyah Malang.
\end{abstract}

Kata Kunci : Iklim etis, Kepemimpinan etis, Efektifitas kepemimpinan 


\section{PENDAHULUAN}

Beberapa kasus yang terjadi saat ini khususnya masalah korupsi di perusahaan dan lembaga publik berdampak kepada kinerja perusahaan dan karyawan. Kasus tersebut terjadi karena ada kelonggaran pengawasan mengenai standar operasional perusahaan, meskipun saat ini beberapa perusahaan membangun sebuah sistem yang solid seperti dijelaskan dalam sebuah survei yang dilakukan pada tahun 2010 di Inggris dan beberapa perusahaan di benua Eropa, terungkap bahwa masalah-masalah yang sedang ramai dibicarakan terhadap organisasi adalah suap, korupsi dan fasilitasi pembayaran, mengenai diskriminasi, pelecehan atau intimidasi (Webley, Basran, Hayward\&Harris, 2011).

Schimmuller (2012) menyatakan bahwa budaya organisasi berpengaruh terhadap kepemimpinan secara positif, negatif atau tidak sama sekali. Inkonsistensi hasil penelitian-penelitian tersebut menunjukkan masih diperlukan penelitian lanjutan untuk mengungkapkan nilai etis perusahaan sebagai bagian dari budaya organisasi dengan lebih baik. Dalam perspektif manajemen, sampai saat ini belum ada teori manajemen yang menjelaskan secara tuntas praktek kepemimpinan (Leadership). Hal ini disebabkan kepemimpinan merupakan tindakan yang abstrak, tetapi banyak menimbulkan perdebatan dalam pelaksanaannya dan mengakibatkan pembahasan kepemimpinan terus berkembang secara dinamis

Iklim etis dianggap sebagai bagian dari budaya organisasi (Boonbongkarn, 2001) dan merupakan faktor kunci untuk menjaga hubungan yang baik antara karyawan dan organisasi, budaya akan membantu untuk memprediksi efektivitas kerja (Ulrich et al., 2007). Iklim etis berarti persepsi bersama yang dapat diterima mengenai perilaku, hubungan, penggunaan kekuasaan, dan standar etika dalam suatu organisasi tanpa pengumuman tertulis.

Persepsi ini dapat mempengaruhi sikap, pengambilan keputusan, dan perilaku etis. Ada lima jenis iklim etis: 1) instrumental, iklim etis yang mendorong kepentingan organisasi; 2) kepedulian, iklim yang mendorong kepedulian dan pertimbangan lainnya; 3) independensi, iklim yang mendorong keputusan menurut keyakinan moral pribadi; 4) aturan, iklim yang menekankan keputusan yang dipandu oleh aturan internal dan peraturan; 5) hukum dan kode, iklim yang mendukung keputusan berdasarkan kode eksternal seperti hukum atau kode etik professional.

Beberapa studi yang dilakukan sebelumnya menunjukkan bahwa iklim etis memiliki hubungan positif dengan kepuasan kerja (Sasomsap, 2004). Minat tim, tanggung jawab sosial, hukum dan iklim kode etik profesional memiliki hubungan positif dengan kepuasan kerja karyawan dan manajer (Elci \& Alpkan, 2009). Ada juga beberapa penelitian tentang iklim etis dan perilaku politik yang menyimpang seperti ambisi pribadi dan pengkhianatan antara rekan kerja (Peterson, 2002 sebagaimana dikutip dalam Appelbaum, Deguire, \& Lay, 2005).

Uraian mengenai permasalahan diatas coba kita uraikan dengan teori Kepemimpinan yang dikemukakan oleh Brown, Trevino \& Harrison (2005) Kepemimpinan etis merupakan demonstrasi perilaku normatif yang tepat melalui tindakan pribadi dan hubungan interpersonal, dan menunjukkan perilaku tersebut kepada para pengikut melalui komunikasi dua arah. Perbedaan kepemimpinan etis dengan kepemimpinan 
lainnya menurut para ahli adalah, kepemimpinan etis lebih menekankan pada internalisasi moral (menghadirkan moralitas dalam perilaku), orang yang bermoral, manajer yang bermoral, dan pengaruh idealisme (Brown dan Trevino, 2006; Walumbwa et al., 2008). Kepemimpinan otentik terdiri dari etika dan kepercayaan (Gardner et al., 2005). Definisi tersebut menunjukkan bahwa efektifitas pemimpin dapat memberi contoh bagi orang lain dan menahan setiap godaan yang mungkin terjadi. Pentingnya karakter yang baik dan nilai-nilai yang tepat, efektifitas pemimpin jauh lebih kompleks dan dampaknya jauh lebih tinggi. Mereka mencoba menghubungkan tujuan dari organisasi dengan karyawan internal dan stakeholders eksternal.

Dalam penelitian ini, pokok permasalahan seperti yang diuraikan diatas adalah bagaimana karyawan merasakan efektifitas kepemimpinan yang terjadi di organisasi tersebut, karena kinerja yang akan mereka hasilkan tentunya berasal dari pengaruh berbagai faktor khususnya dari pengaruh kepemimpinan tersebut. Hal ini nantinya akan berpengaruh terhadap layanan yang akan diberikan kepada masyarakat umum yang menggunakan jasa dari RS UMM. Obyek penelitian adalah karyawan RS UMM yang identik dengan nilai keislaman. Berdasarkan penjelasan ini, RS UMM masih mempunyai tanggung jawab yang besar dan masih ada kekurangan dalam hal peningkatan status td yang mana kinerja dan pelayanan yang diberikan sangat tergantung berdasarkan faktor kepemimpinan. Penelitian ini mengambil objek di RS Universitas Muhammadiyah Malang sebagai bagian dari Amal Usaha Muhammadiyah dan sebagai cerminan bagaimana faktor kepemimpinan dan iklim etis yang ada mempengaruhi efektifitas kepemimpinan.

\section{Kajian Pustaka}

Iklim Etis

Iklim etis adalah istilah yang mengacu pada sekumpulan norma dalam suatu organisasi yang menentukan cara perilaku individu dalam organisasi memutuskan apa yang etis dan tidak etis. Iklim etika berfokus pada proses pengambilan keputusan etis daripada keputusan etis itu sendiri. Lima tipe iklim etis tersebut adalah caring, law and code, rules, instrumental and independency. Iklim kepedulian dicirikan oleh organisasi yang peduli terhadap semua orang di perusahaan secara keseluruhan, dan mengharapkan setiap orang untuk melakukan apa yang benar terhadap pelanggan dan publik. Tipe iklim hukum dan kode digambarkan sebagai iklim yang diharapkan untuk secara ketat mengikuti standar hukum dan profesional di atas dan di atas pertimbangan lainnya. Tipe iklim aturan menekankan aturan dan prosedur perusahaan. Karyawan diharapkan untuk secara ketat mematuhi kebijakan perusahaan. Tipe iklim instrumental ditandai oleh karyawan yang diharapkan melakukan apa pun untuk memajukan kepentingan perusahaan, terlepas dari konsekuensinya. Umumnya, orang-orang di iklim instrumental melindungi kepentingan mereka sendiri di atas segalanya. Tipe iklim etika terakhir adalah independensi. Tipe iklim ini memungkinkan karyawan untuk memutuskan sendiri apa yang benar dan salah, dengan demikian orang dibimbing oleh etika mereka sendiri.

Cullen (1988) mengembangkan tipologi sembilan tipe iklim etis, kesembilan tipe itu mungkin dalam organisasi, tetapi lima tipe paling sering digunakan dalam suatu organisasi (Simha \& Cullen, 2012). Kelima tipe iklim ini telah dipelajari oleh sejumlah penulis dan hasilnya menunjukkan bahwa iklim etis berhubungan negatif dengan masalah etika yang melibatkan manajemen sumber daya (Bartels, Harrick, Martell \& 
Strickland, 1998), iklim etis berhubungan positif dengan pekerjaan kepuasan (Tsai \& Huang, 2008; Wang \& Hsieh, 2012) dan komitmen organisasi (Bulutlar \& Oz, 2009; Shafer, 2009), dan iklim etis berhubungan negatif dengan frekuensi absensi (ShapiroLischinsky \& Rosenblatt, 2009).

\section{Kepemimpinan Etis}

Penelitian Shirbagi (2007) menunjukkan bahwa gaya kepemimpinan berpengaruh terhadap komitmen karyawan, baik komitmen afektif, komitmen normatif dan komitmen kontinuan. Hal serupa juga ditunjukkan oleh penelitian Hasanah (2017) yang menunjukkan bahwa gaya kepemimpinan dapat meningkatkan kinerja karyawan. Keberhasilan suatu organisasi dapat ditentukan faktor eksternal dan internal perusahaan. Tenaga kerja merupakan faktor yang penting bagi kelangsungan perusahaan karena manusia merupakan penggerak bagi sumber daya perusahaan lainnya. Temuan Shirbagi ini bertentangan dengan penelitian Ramchandran dan Khrisnan (2009) yang menyatakan bahwa hanya komitmen afektif yang penting bagi karyawan ketika sikap yang terbentuk menunjukkan ikatan emosional dengan organisasi.

Dua variabel penting adalah isu kepemimpinan etis dalam meningkatkan prestasi kerja karyawan, kepercayaan dan komitmen karyawan. Seperti terlihat dalam pernyataan beberapa peneliti (Hosmer, 1994; Jones, 1995 dikutip dalam Berrone et al., 2007.) bahwa etika yang baik adalah menghasilkan eksternalitas positif seperti kepercayaan dan komitmen kepada semua pemangku kepentingan, yang pada gilirannya menjamin kinerja jangka panjang perusahaan.

Kepercayaan adalah dasar untuk konflik yang konstruktif, komitmen bertujuan, akuntabilitas pribadi, dan mencapai tujuan kolektif (Lencioni, 2005 dikutip dalam Collins, 2010). Menurut Jones \& George (1998) dikutip dalam Zhu, Mei \& Avolio (2004) ada dua jenis kepercayaan : bersyarat dan tanpa syarat. kepercayaan bersyarat adalah situasi dimana kedua belah pihak bersedia untuk bertransaksi dengan satu sama lain selama setiap berperilaku secara tepat dan menggunakan skema interpretatif mirip dengan mendefinisikan situasi. Sedangkan kepercayaan bersyarat ditandai oleh nilai-nilai bersama yang struktur situasi sosial dan menjadi kendaraan utama melalui mana individu mengalami kepercayaan.

\section{Efektifitas Kepemimpinan}

Selama beberapa dekade, para peneliti kepemimpinan telah bekerja untuk menentukan efektivitas kepemimpinan dan memahami komponen apa yang berkontribusi pada seorang pemimpin yang efektif. Hasil-hasil efektivitas pemimpin berbeda di antara para peneliti, menurut Dhar dan Mishra (2015) efektivitas kepemimpinan adalah hasil ketika individu dalam posisi kepemimpinan dapat mempengaruhi kelompok untuk melakukan peran mereka dengan hasil organisasi yang positif. Sebagaimana dinyatakan oleh Madanchian, Husein (2010) jika seorang pemimpin dapat mempengaruhi bawahannya atau unitnya sedemikian rupa sehingga hasil positif direalisasikan, pemimpin dapat disebut sebagai pemimpin yang efektif.

Karena hasil yang tidak konsisten antara tiga dimensi kepemimpinan etis dalam studi De Hoogh dan Den Hartog, penelitian ini mengikuti pendekatan yang dibuat oleh Brown dan Trevino (2008). Dhar dan Mishra mencatat bahwa manajemen kelompok yang efisien dan efektif dapat memiliki efek langsung pada hasil dengan memfasilitasi keputusan dan arahan yang tepat waktu dan berkualitas oleh pemimpin atau hasil tidak langsung ketika tindakan pemimpin secara 
positif mempengaruhi perilaku dan dinamika kelompok. Oleh karena itu, penelitian ini, menggunakan ukuran Dhar dan Mishra tentang efektivitas pemimpin dalam organisasi layanan. Penilaian Dhar dan Mishra meminta bawahan pemimpin untuk mengevaluasi efektivitas pemimpin, jadi, penelitian ini mengadopsi empat dimensi penilaian mereka berdasarkan kemampuan pemimpin untuk menginspirasi, memfasilitasi, memotivasi dan mempengaruhi kinerja bawahan.

Dari hasil pembahasan di atas, model penelitian ini dapat ditunjukkan pada gambar 1 berikut.

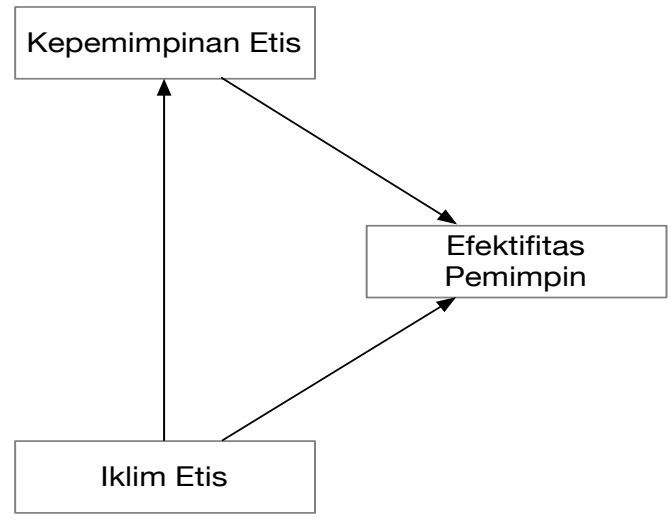

Gambar 1 : Kerangka Penelitian

Sumber: diolah Penulis, 2019

\section{METODE PENELITIAN}

Jenis \& Lokasi Penelitian

Penelitian ini menggunakan metode pendekatan positivist atau kuantitatif karena bertujuan menguji hipotesis. Jenis perusahaan adalah Rumah Sakit yang terdapat di Kota Malang. Status perusahaan adalah perusahaan yang berada dibawah naungan Universitas Muhammadiyah Malang.

\section{Populasi dan Sampel Penelitian}

Populasi penelitian ini (unit analisis) adalah seluruh karyawan selain unsur pimpinan (Kepala Pelayanan Medik) yang mempunyai tugas dan tanggung jawab berkaitan dengan pelaksanaan operasional perusahaan. Populasi yang digunakan dalam penelitian ini adalah seluruh karyawan sejumlah 200 orang yang tercatat sebagai karyawan tetap di RS tersebut khususnya yang berada di divisi pelayanan medik bidang keperawatan. Karyawan tetap RS ini adalah orang yang melayani seluruh aktifitas dan kegiatan RS tersebut. Penelitian ini menggunakan teknik pengambilan sampel dikarenakan peneliti tidak mampu menjangkau keseluruhan populasi. Pengambilan sampel yang digunakan adalah nonprobability sampling dengan teknik sampling purposive yaitu teknik penetuan sampel dengan pertimbangan tertentu.

\section{Pengembangan Konstruk Penelitian}

Variabel-variabel dalam penelitian ini dikategorikan sebagai variabel eksogen (independen) dan variabel endogen (dependen). Variabel eksogen adalah: iklim etis (X1) dan kepemimpinan etis (X2). Variabel endogen yaitu efektifitas kepemimpinan (Y1). Setiap variabel adalah variabel laten yang diukur dari beberapa variabel indikator (terobservasi) yang bersifat reflektif. Tiap-tiap variabel indikator dijabarkan dalam butir-butir pertanyaan dan secara keseluruhan terdapat dalam indikator. Pengukuran data 
Pengukuran data variabel indikator menggunakan skala Likert dengan interval penilaian mulai dari skor 1 (sangat tidak setuju) sampai dengan skor 5 (sangat setuju) (Sekaran, 2006). Data penelitian ini dikumpulkan dari sumber primer dan sekunder. Data primer diperoleh dengan membagikan kuesioner dan wawancara kepada seluruh karyawan yang bukan kategori pemimpin perusahaan sesuai dengan populasi yang sudah ditentukan. Daftar pertanyaan di dalam kuesioner disusun berdasarkan indikator-indikator variabel penelitian.

\section{Metode Analisis Data}

Penelitian ini menggunakan pendekatan analisis Partial Lease Square (PLS). PLS menggunakan metode bootstraping atau penggandaan secara acak. Oleh karenanya asumsi normalitas tidak akan menjadi masalah bagi PLS. Selain terkait dengan normalitas data, dengan dilakukannya bootstraping maka PLS tidak mensyaratkan jumlah minimum sampel. Penelitian yang memiliki sampel kecil dapat tetap menggunakan PLS.

\section{HASIL DAN PEMBAHASAN}

Hasil

Teknik analisis data pada penelitian ini menggunakan partial least square (PLS) dengan alat analisis SmartPLS 3.0. Analisis data dengan PLS terdiri dari dua tahap yakni evaluasi model pengukuran (outer model) dan evaluasi model struktural (inner model).Evaluasi outer model terdiri dari tiga kriteria yaitu validitas konvergen, validitas diskriminan dan composite reliability. Pada perhitungan convergent validity kriteria minimal loading factor sebesar 0,50, (Chin dalam Ghozali, 2014). Discriminant validity diukur dengan membandingkan akar kuadrat dari AVE untuk setiap konstruk dengan nilai korelasi antar konstruk dalam model. Validitas discriminant yang baik yaitu akar kuadrat dari AVE untuk setiap konstruk lebih besar dari korelasi antar konstruk dalam model. Jika nilai akar AVE lebih tinggi daripada nilai korelasi di antara konstruk, maka discriminant validity yang baik telah tercapai. Pengujian selanjutnya untuk menganalisis outer model adalah dengan melihat reliabilitas konstruk variabel laten yang diukur dengan dua kriteria yaitu composite reliability dan cronbach alpha dari blok indikator yang mengukur konstruk. Konstruk dinyatakan reliabel jika nilai composite reliability maupun nilai cronbach alpha diatas 0,70. Berikut hasil output composite reliability dan cronbach alpha :

Tabel 1. Nilai faktor loading (convergent validity) dari setiap indikator

\begin{tabular}{|l|l|l|l|}
\hline Variable & Original Sample (O) & Standard Deviation (STDEV) & T Statistics \\
\hline X1.1 -> Iklim Etis & 0,622 & 0,193 & 11,215 \\
\hline X1.2-> Iklim Etis & 0,756 & 0,054 & 23,923 \\
\hline X1.3 -> Iklim Etis & 0,769 & 0,033 & 25,632 \\
\hline X1.4 -> Iklim Etis & 0,982 & 0,006 & 133,754 \\
\hline X1.5 -> Iklim Etis & 0,973 & 0,012 & 92,505 \\
\hline X1.6 -> Iklim Etis & 0,975 & 0,002 & 112,507 \\
\hline Z1.1-> Kepimpinan Etis & 0,937 & 0,023 & 36,543 \\
\hline Z1.2-> Kepimpinan Etis & 0,975 & 0,014 & 32,436 \\
\hline Z1.3-> Kepimpinan Etis & 0,793 & 0,045 & 35,566 \\
\hline Z1.4-> Kepimpinan Etis & 0,672 & 0,152 & 20,892 \\
\hline Y1.1-> Efektifitas Pemimpin & 0,504 & 0,186 & 9,276 \\
\hline Y1.2-> Efektifitas Pemimpin & 0,832 & 0,024 & 18,384 \\
\hline Y1.3-> Efektifitas Pemimpin & 0,689 & 0,015 & 23,381 \\
\hline
\end{tabular}

Sumber: Data diolah, 2019 


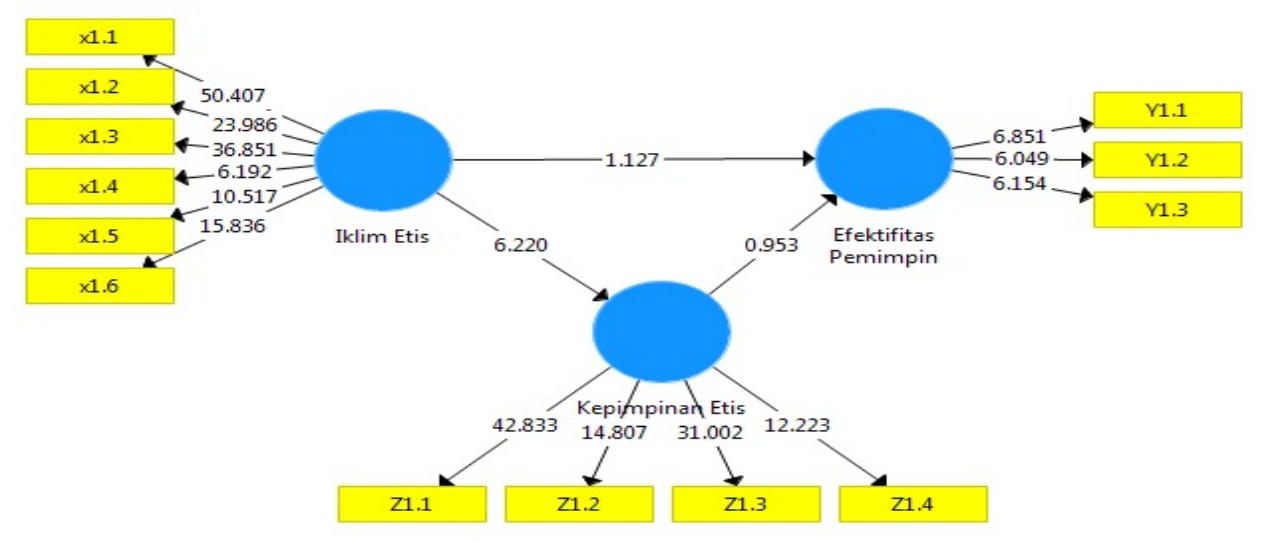

Gambar 2. Model Struktural (Inner Model) Source: SmartPLS (2019)

Tabel 1 pada output tersebut menggambarkan nilai faktor loading (convergent validity) dari setiap indikator. Nilai faktor loading $>0,7$ dapat dikatakan valid, akan tetapi rule of thumbs intrepretasi nilai faktor loading $>0,5$ dapat dikatakan valid. Dari tabel tersebut, diketahui bahwa semua nilai faktor loading dari indikator Iklim Etis (X1), Kepimpinan Etis (Z1), dan Efektifitas Pemimpin (Y2) lebih besar dari
0,60 . Hal ini menunjukkan bahwa indikatorindikator tersebut valid. Pengujian inner model atau model struktural dilakukan untuk melihat hubungan antara konstruk nilai signifikansi dan R-square dari model penelitian. Model struktural dievaluasi dengan menggunakan R-square untuk konstruk dependen uji t serta signifikansi dari koefisien parameter jalur struktural.

Tabel 2. R-Square

\begin{tabular}{|c|c|}
\hline Variabel & R Square \\
\hline Y1 & 0.665 \\
\hline
\end{tabular}

Sumber: PLS (2019)

Tabel 3. Hasil analisis Jalur

\begin{tabular}{|l|l|l|l|}
\hline Variable & $\begin{array}{l}\text { Original } \\
\text { Sample (O) }\end{array}$ & $\begin{array}{l}\text { Standard } \\
\text { Deviation (STDEV) }\end{array}$ & $\begin{array}{l}\text { T Statistics } \\
\text { (|O/STERR|) }\end{array}$ \\
\hline Iklim Etis -> Efektifitas Pemimpin & 1,127 & 0,152 & 3,682 \\
\hline Iklim Etis -> Kepimpinan Etis & 6,220 & 0,122 & 7,105 \\
\hline Kepimpinan Etis -> Efektifitas Pemimpin & 0,953 & 0,128 & 2,481 \\
\hline
\end{tabular}

Sumber: PLS (2019)

Tabel 2 menunjukkan nilai R-Square untuk Efektifitas Pemimpin diperoleh sebesar 0,665. Hal ini menunjukkan bahwa sebesar 66,5\% variabel Efektifitas Pemimpin dipengaruhi oleh Kepimpinan Etis dan Iklim Etis. Sisanya sebesar 33,5\% dipengaruhi oleh variabel lain yang diteliti. Pada penelitian ini juga dilakukan metode bootstrap terhadap sampel. Pengujian dengan bootstrap juga dimaksudkan untuk meminimalkan masalah ketidaknormalan data penelitian. Hasil pengujian dengan bootstrapping dari analisis PLS dapat dilihat pada tabel 3:

Signifikansi parameter yang diestimasi 
memberikan informasi yang sangat berguna mengenai hubungan antara variabel-variabel penelitian. Dasar yang digunakan dalam menguji hipotesis adalah nilai yang terdapat pada output result for inner weight. Pengujian hipotesis dapat dilakukan dengan membandingkan $\mathrm{t}$-statistik dengan $\mathrm{t}$-tabel. $\mathrm{t}$ tabel dapat diperoleh dari 133 sampel yang pada akhirnya didapatkan t-tabel sebesar 1,960. Maka dapat disimpulkan bahwa hasil analisis terhadap pengujian hipotesis adalah $\mathrm{H} 1$ diterima dan $\mathrm{H} 2$, serta $\mathrm{H} 3$ ditolak

\section{Pembahasan}

Hipotesis 1 menunjukkan bahwa hubungan variabel Iklim Etis (X1) dengan Efektifitas Kepimpinan (Y1) menunjukkan nilai koefisien jalur sebesar 1,127 dengan nilai $t$ sebesar 3,682. Nilai tersebut lebih besar dari $t$ tabel $(1,960)$. Hasil ini berarti bahwa Iklim Etis memiliki pengaruh positif dan signifikan terhadap Efektifitas Pemimpin. Hal ini berarti bahwa semakin besar iklim etis yang ada pada Rumah Sakit Muhammadiyah Malang maka Efektifitas Pemimpin yang ada cenderung semakin baik. Hal ini juga berarti bahwa iklim etis mampu memperkuat hubungan antara penerimaan organisasi terhadap identifikasi pemimpin.

Penelitian ini sejalan dengan penelitian Ayla (2012) dalam penelitiannya yang dilakukan di Turki menyatakan bahwa iklim etis terbukti mampu memperkuat hubungan antara penerimaan organisasi terhadap identifikasi organisasi. Selain itu, Yener (2012) yang meneliti mengenai hubungan antara iklim etis terhadap kesesuaian kerja juga mendapatkan pengaruh yang positif. Hal ini membuktikan bahwa dengan adanya iklim etis yang baik mampu mempengaruhi efektifitas pemimpin

Hipotesis 2 menunjukkan bahwa hubungan variabel Iklim Etis (X1) dengan Kepimpinan Etis (Z1) menunjukkan nilai koefisien jalur sebesar 6,220 dengan nilai $t$ sebesar 7,105. Nilai tersebut lebih besar dari t tabel (1,960). Hasil ini berarti bahwa Iklim Etis memiliki pengaruh yang positif dan signifikan terhadap Kepimpinan Etis yang berarti sesuai dengan hipotesis pertama dimana Iklim Etis berpengaruh signifikan terhadap Kepimpinan Etis. Hal ini berarti bahwa semakin besar iklim etis maka kepimpinan etis cenderung semakin besar pula. Hal ini juga berarti bahwa Rumah Sakit Universitas Muhammadiyah Malang mampu mendrong iklim yang etis untuk mendorong kepentingan organisasi.

Pemimpin pada Rumah Sakit Universitas Muhammadiyah Malang yang menunjukkan perilaku etis akan lebih mungkin untuk mempertimbangkan kebutuhan dan hak karyawan dan memperlakukan mereka dengan adil. Memang setiap karyawan ingin bekerja untuk kepada pemimpin perusahaan yang mengutamakan perilaku etis (Collins, 2010; Trevino \& Brown, 2004, Upadhyay \& Singh, 2010) kepemimpinan etis berhubungan erat dengan aktualisasi diri, hubungan moral dan kesepakatan yang jelas antara pemimpin dan karyawan (Gardner, 2005).

Hipotesis 3 menunjukkan bahwa hubungan variabel Kepimpinan Etis (Z1) dengan Efektifitas Pemimpin menunjukkan nilai koefisien jalur sebesar 0,953 dengan nilai $\mathrm{t}$ sebesar 2,481. Nilai tersebut lebih besar dari $t$ tabel $(1,960)$. Hasil ini berarti bahwa Kepimpinan etis memiliki pengaruh yang positif dan signifikan secara langsung terhadap efektifitas pemimpin. Hal ini juga berarti bahwa Rumah sakit Muhammadiyah Malang memiliki pemimpin yang etis dengan dapat menciptakan efektifitas kepimpinan dengan menginspirasi, memfasilitasi, memotivasi dan mempengaruhi kinerja karyawannya.

Kepemimpinan etis menunjukkan bahwa kombinasi dari integritas, standar etika, dan perlakuan yang adil itulah kepemimpinan 
etis. Pencegahan kepercayaan didasarkan pada takut pembalasan jika kepercayaan dilanggar. Tindakan individu sesuai dengan apa yang mereka katakan karena konsekuensinya. Pengetahuan kepercayaan didasarkan pada prediktabilitas perilaku yang berasal dari sejarah interaksi. Kepercayaan berdasarkan identifikasi berada pada saling pengertian satu sama lain keinginan. Kepercayaan merupakan masalah penting dalam organisasi yang memiliki efek pada kinerja, dan jika rusak cenderung memiliki efek serius yang berlawanan. kepercayaan karyawan kepada pemimpin kemungkinan akan menghasilkan peningkatan kepatuhan karyawan dengan organisasi, aturan dan hukum, memfasilitasi pelaksanaan perubahan organisasi, dan meningkatkan kontribusi karyawan dalam hal kinerja (Robbinson 1996; Van Zyl \& Lazeny 2002 dikutip dalam Ponnu \& Tennakoon, 2009).

\section{KESIMPULAN DAN SARAN}

\section{Kesimpulan}

Berdasarkan hasil analisis penelitian baik secara deskriptif maupun dengan perhitungan menggunakan Smart PLS yang telah diuraikan pada bab sebelumnya, dapat disimpulkan beberapa hal sebagai berikut.

Hasil analisis menunjukkan bahwa variabel iklim etis berpengaruh signifikan terhadap kepimpinan etis. Hasil tersebut menjelaskan bahwa iklim etis yang ada pada Rumah Sakit Muhammadiyah Malang mempunyai norma yang etis dalam menentukan kepentingan yang etis pada organisasi dan mendorong keputusan yang dipandu sesuai aturan internal dan peraturan yang ada. Iklim etis juga berpengaruh positif dan signidikan terhadap kepimpinan etis. Hal itu menunjukkan bahwa pada Rumah Sakit Muhammadiyah Malang mempunyai kombinasi dari integritas, standar etika, dan perlakuan yang adil. Kepimpinan etis juga berpengaruh positif dan signidikan terhadap efektifitas pemimpin. Hal itu menunjukkan terdapat efektivitas pemimpin dalam organisasi layanan Rumah Sakit Muhammadiyah Malang serta menunjukkan bawahan untuk mengevaluasi efektivitas pemimpin.

\section{Saran}

Berdasarkan keterbatasan penelitian ini, terdapat beberapa saran untuk manajemen Rumah Sakit Muhammadiyah Malang yaitu penelitian ini menunjukkan bahwa karyawan memerlukan sosok yang inspirasi, dapat memfasilitasi, memotivasi serta mempengaruhi kinerja bawahan untuk meningkatkan kinerja bawahan.

\section{DAFTAR PUSTAKA}

Dasaad. 2015. Analisis hubungan kepimpinan dan kepuasan kerja terhadap kinerja karyawan pada PT. Adam Jaya. Jurnal Ekonomi Bisnis. 20 (1), 8-15.

Dirani, K.M. 2009. Measuring the learning organization culture, organization commitment and job satisfaction in the Lebanese banking sector. Human Resource Development International, 12(2), 189-208.

Dukoulou, P. and Trivellas, P. 2015. Measuring the impact of learning organization on job satisfaction and individual performance in greek advertising sector. Social and Behavioral Science, 175, 367-375.

Egan, T.M., Yang, B., \& Bartlett, K.R. 2004. The effects of organizational learning culture and job satisfaction on motivation to transfer learning and turnover intention. Human Resource Development Quarterly, 15, 279-301. Ghozali, Imam. 2011. Partial Least Squares. Konsep Teknik dan Aplikasi. Semarang : Badan Penerbit, Universitas Diponegoro 
Hasanah, N. (2018). ANALISIS

PENGARUH GAYA KEPEMIMPINAN

DAN KOMPENSASI TERHADAP

KINERJA KARYAWAN (STUDI

KASUS PADA PT. FINANSIA MULTI

FINANCE CABANG

BANJARMASIN). At-Tadbir: jurnal ilmiah manajemen, 2(1).

Jenkins, A. K. (2009). Keeping the talent: Understanding the needs of engineers and scientists in the defense acquisition workforce. Defense Acquisition Review Journal, 16(1), 1-19.
Mayer, D. M. , Kuenzi, M. , Greenbaum, R. L. (2009). Making Ethical Climate a Mainstream Management Topic: A Review, Critique, and Prescription for the Empirical Research on Ethical Climate. Chapter to appear in D. De Cremer (Ed.), Psychological perspectives on ethical behavior and decision making. Greenwich, CT: Information Age Publishing Rothwell, G. R., \& Baldwin, J. N. (2006a). Ethical Climate Theory, whistleblowing, and the code of silence in police agencies in the State of Georgia. (2006). Journal of Business Ethics70, 341-361. 